\title{
Growing Minds: The Relationship Between Parental Attitudes Toward Their Child's Outdoor Recreation and Their Child's Health
}

\author{
Danielle E. Hammond ${ }^{1}$, Amy L. McFarland², Jayne M. Zajicek², \\ and Tina M. Waliczek ${ }^{4,5}$
}

AdDitional INDEX wORDs. play, nature, obesity, asthma, gardening, type II diabetes, nutrition, diet

SUMMARY. The objective of this study was to investigate the relationship between parental attitudes toward nature and their child's outdoor recreation and how these attitudes related to their reports of their child's health problems. The sample for this study consisted of parents of 6- to 13-year-old children from the United States, who accessed the survey from an informational website for gardeners between Mar. and Aug. 2009. Surveys were collected until 142 completed questionnaires were received. The online survey included questions about parents' attitude toward nature, parents' attitudes toward their child's outdoor recreation, an inventory of potential children's health problems, the time children spent in various indoor and outdoor activities, and demographic questions. Descriptive statistics were used to tabulate mean scores on the parental attitude toward nature (PAN) scale and parental attitude toward their child's outdoor recreation (PACOR) scale, both of which indicated overall positive views. Pearson's product-moment correlations indicated statistically significant relationships between the PAN scale, the PACOR scale, and time children spent outdoors. Relationships between time spent indoors on video games or watching television and health problems in children were identified. Time spent outdoors in free play was inversely related to reports of health problems in children.

$\mathrm{H}$ ealth problems in children and adults have become an increasing concern in the United States. According to the $\mathrm{Na}$ tional Center for Health Statistics, one major concern is the prevalence of asthma, which has continued to remain historically high after the drastic increase in asthma between the 1980s and late 1990s (Akinbami, 2006). Another major health concern on the rise is obesity. One survey stated that almost $74 \%$ of American adults are either overweight or obese (National Center for Health Statistics, 2010a). Between 1988 and 2004, the number of overweight children between the ages of 2 and 5 years had increased from $7.2 \%$ to $13.9 \%$ and the number of overweight

${ }^{1}$ Graduate Assistant, Department of Horticulture, Forestry \& Recreation Resources, Kansas State University, Manhattan, KS 66506

${ }^{2}$ Graduate Assistant, Department of Horticultural Sciences, Texas A\&M University, College Station, TX 77843-2133

${ }^{3}$ Professor, Department of Horticultural Sciences, Texas A\&M University, College Station, TX 778432133

${ }^{4}$ Professor, Department of Agriculture, Texas State University-San Marcos, San Marcos, TX 78666

${ }^{5}$ Corresponding author. E-mail: tcl0@txstate.edu. children between the ages of 6 and 19 years increased from $11 \%$ to $19 \%$ (National Center for Health Statistics, $2010 b$ ). In a study conducted on children under the age of 13 years, it was found that only $\approx 0.5 \mathrm{~h}$ per week was spent in outdoor activities such as gardening, picnicking, walking, and hiking, whereas $\approx 12 \mathrm{~h}$ per week were spent indoors watching television (Hofferth and Sandberg, 2001). This is a stark contrast to the reports of mothers who spent time outdoors on a daily basis (Clements, 2004).

Even with the reports of positive health benefits from spending time outdoors, children are spending increasingly more time indoors (Juster et al., 2004). Several studies suggested that outdoor safety issues are a large concern for parents (Farley et al., 2007; Valentine and McKendrick, 1997). These concerns include potential accidents, abduction, and interactions with violent strangers. In addition, parents were concerned about keeping children safe from criminal activity (Valentine and McKendrick, 1997). In each of these studies, parental concerns were directly related to the activity in which their children participated. When children were provided with a safe and quality play area, Farley et al. (2007) found that there was an increase in the total number of children spending time outdoors. This suggested that one solution to increasing quality outdoor activities for children may be to provide a quality, safe, and nearby public green space.

The increase in time spent indoors negatively affects children's dietary habits. Children who stayed inside and watched more television tended to eat fewer fruit and vegetables and consumed other low nutrition foods instead (Coon et al., 2001). Because of these dietary trends, a decreased amount of time spent outdoors has been associated with obesity in a variety of ways. More television viewing has been connected with greater gain of body fat in children, especially when it was combined with a sedentary lifestyle (Proctor et al., 2003). Children who watched more television reported eating more total calories in comparison with children who watched less television (Blass et al., 2006; Coon et al., 2001). In contrast, children who spent more time playing outdoors reported higher amounts of physical activity and tended to have a lower body mass index (Ludvigsson et al., 2007).

The decrease in amount of time spent outdoors has other health effects. One reported effect is that exposure to indoor allergens, rather than outdoor allergens, significantly contributed to the development of asthma (Halken, 2003). Furthermore, with decreased time outdoors, children spend more time sitting in front of the television or playing video games, and the combination of decreased physical activity and increased exposure to indoor allergens cause an increase in asthma development (Ring et al., 2001). According to the American Academy of Allergy Asthma and Immunology $(2007), \approx 50$ million people in the United States are affected with allergies of some sort. Allergic disease is the fifth most common disease throughout all ages and the third most common chronic disease in children under 18 years old (American Academy of Allergy Asthma and Immunology, 2007). Akinbami (2006) found that about half of all citizens of the United States tested positive for at least one allergen.

Health benefits from spending time outdoors are not just limited to 
reductions in allergies and weight. Studies have shown that spending time outdoors and around green spaces can reduce stress in adults and children. For example, just walking through a botanic garden was shown to be effective in reducing stress (Wells and Evans, 2003). Also, in another study, children who were around more natural conditions rated their self-worth higher and they reported less adverse impacts from stressful events (Kohlleppel et al., 2002).

The purpose of this study was to investigate the relationship between attitudes of parents toward outdoor environments, their children spending time outdoors, and how these attitudes related to their children's overall health.

\section{Materials and methods}

Each section of the questionnaire was evaluated by researchers in social and horticultural sciences for face and content validity before the survey was posted online.

SAmple. The sample for this study consisted of parents or guardians of 6- to 13-year-old children from across the United States who accessed the survey from an informational website for gardeners between Mar. and Aug. 2009. Respondents learned of the survey from visiting this website designed to provide information about lawn care, tree care, vegetable and ornamental gardening, and school gardens. This website received an average of almost 900,000 page requests per day (Texas A\&M University, 2009). Surveys were continuously collected with 142 completed questionnaires received. Two responses were from individuals outside the United States and were removed from data analysis. Thus, 140 responses were used for the final data analysis. According to Cohen (1992), 140 responses should yield a power of 0.80 with a small-to-medium effect size at $\alpha=0.05$.

Parental attitude instrumenTATION. Two measures of parental attitude were used in this study. The PAN instrument included 21 questions pertaining to attitudes parents have toward nature, and the PACOR scale included 29 statements relating to their attitude toward their children spending time outdoors (McFarland et al., 2011). These questions were adapted from other studies about attitudes toward nature and their children's activities (Ennis, 2003; McMillan, 2003; Murphy, 1984; Piotrowoski, 2007; Skelly, 1997; Timperio et al., 2004; Weir et al., 2006). Parents responded to statements on both scales on a six-point Likert-type scale (Likert, 1967). Possible responses included "strongly agree" (which scored 6 points), "somewhat agree" (5 points), "slightly agree" (4 points), "slightly disagree" (3 points), "somewhat disagree" ( 2 points), and "strongly disagree" (1 point). Negatively worded statements were reverse coded such that the more positive response scored the higher points to allow for proper data analysis. Non-responses to any question received no points for that question. The PAN scale had a possible range of 21 through 126 with a higher score indicating a more positive view toward nature. The PACOR scale had a possible range of 29 through 174 with higher scores indicating more positive views toward their child's outdoor recreation.

ChILdREN'S HEALTH PROBLEMS InSTRUMENTATION. The health inventory section of the instrument was developed with questions adapted from several health inventories and was designed to measure children's general health (Liberatos, 2007; Welsh, 2006). Questions were drawn from Liberatos' (2007) questionnaire, which investigated children's health with an inventory developed by children's health practitioners. Liberatos' (2007) questionnaire was pretested by pediatricians and was found to be valid and reliable. Parents were asked to respond in a "yes" or "no" fashion to possible symptoms and health problems. The checklist was reworded to ask about reoccurring problems so as to target longterm health problems for this study. The health problems section was scored by taking a cumulative sum of the responses, with responses of "yes" being worth 1 point each and "no" answers were equivalent to 0 points. The possible range of scores for the health inventory section was 0 through 24, with higher scores indicating more reported health problems. No parents indicated that their child had experienced reoccurring problems with dizziness, weight loss of $10 \mathrm{lb}(4.5 \mathrm{~kg})$ or more, or eating disorders, and these statements were removed from data analysis.
Demographic instrumentaTION. Standard demographic questions were asked about the respondent's and child's gender, child's age, child's ethnicity, and parent/guardian marital status. This section also asked parents to describe the area they live as "inner city," "urban," "suburban," or "rural." Parents were asked to quantify the number of hours per day their children spent in outdoor free play, outdoor organized activities or sports, indoor organized activities or sports, and indoor video game play or watching television. Possible responses included " $0-1$ h," "l-2 h," and " $2+$ h." The demographic section was patterned after similar instruments (Dravigne et al., 2008; Waliczek et al., 1996). Parents were also asked to indicate their home addresses so that an incentive of a wildflower seed packet could be sent if desired. The IP address of each respondent was also recorded to remove any duplicate responses. All identifying information was separated from responses upon downloading the data so that participant responses could not be attached to any individual.

Data analysis. After the survey was available online for 5 months, data were automatically downloaded into an Excel spreadsheet (Microsoft, Redmond, WA) and then transferred and analyzed using SPSS ${ }^{\circledR}$ (version 15.0; SPSS, Chicago). A Cronbach's alpha reliability coefficient for each section of the survey was calculated to ensure that each measure had sufficient internal consistency. A Cronbach's reliability analysis of the PAN scale yielded a high reliability $(\alpha=$ $0.87)$. The PACOR scale also yielded a high reliability $(\alpha=0.87)$ (Gall et al., 2006). Statistical analyses included descriptive statistics, frequencies, and Pearson's product-moment correlations.

\section{Results and discussion}

Parental attitudes. The PAN scale scores ranged from 67 to 124 and the PACOR scale scores ranged from 98 to 173. The mean score for PAN scale was 109.37 with a SD of 10.97. The per question mean was 5.21 with an average per question range of 3-6. For the PACOR scale, the mean score was 151.54 with a SD of 13.57. The mean score per question was 5.23 with a per question average range of 3-6. This indicated 
that most respondents answered most statements as either "somewhat agree" or "strongly agree," which suggested that parents reported an overall positive view about nature and their child's outdoor recreation. These findings suggested that most of these parents enjoyed looking at and learning about nature and enjoyed being in outdoor settings. These findings were in accordance with other studies, which have shown that people enjoy nature and natural settings (Chawla, 2002; Frumkin, 2001; Korpela 2002). These findings also indicated that despite possible dangers that their children may encounter outdoors, parents in this sample were still positive about their children spending time outdoors. Studies have shown that safety factors can influence parents as to where they let their children play, and concerns related to traffic, abduction, gangs, and violent strangers may persuade parents that the outdoor environment is not a good place in which their children should play (Farley et al., 2007; Molnar et al., 2004; Valentine and McKendrick, 1997; Veitch et al., 2006). However, in this study, these concerns did not appear to be an overriding factor in whether parents felt good about letting their children play outdoors.

Time SPENT INDOORS AND OUTDOORS AND OVERALL HEALTH. A Pearson's product-moment correlation was calculated among the combined time spent indoor scores, the combined time spent outdoor scores, and total number of child's reported health problems. Total time spent outdoors was negatively correlated with reports of several individual health problems (Table 1). This research supports that of Watanabe et al. (2006), who also found that outdoor play could be associated with preventing different illnesses in children.

The total time spent indoor score was positively correlated with the health problem score, nasal congestion, asthma attacks, trouble sleeping, diabetes, and frequent swollen glands (Table 1). This indicated that as the children's reported number of total hours spent indoors increased, the overall number of health problems reported increased. Also, reports of specific health problems increased, which included nasal congestion, asthma attacks, trouble sleeping, diabetes, and frequent swollen glands. These findings offer further

Table 1. Correlation matrix indicating the Pearson's product-moment correlation between the total indoor time score, the total outdoor time score, and health problems in the study of the relationship between parental attitudes toward their child's outdoor recreation and their child's health.

\begin{tabular}{|c|c|c|c|}
\hline Health problem & & $\begin{array}{l}\text { Total indoor } \\
\text { time score }\end{array}$ & $\begin{array}{c}\text { Total outdoor } \\
\text { time score }\end{array}$ \\
\hline Overall $^{x}$ & $\begin{array}{l}\text { Pearson correlation } \\
P\end{array}$ & $\begin{array}{l}0.20^{*} \\
0.02\end{array}$ & $\begin{array}{r}-0.03 \\
0.703\end{array}$ \\
\hline Nasal congestion & $\begin{array}{l}\text { Pearson correlation } \\
P\end{array}$ & $\begin{array}{l}0.22 * \\
0.01\end{array}$ & $\begin{array}{l}0.13 \\
0.14\end{array}$ \\
\hline Asthma attacks & $\begin{array}{l}\text { Pearson correlation } \\
P\end{array}$ & $\begin{array}{l}0.17^{*} \\
0.04\end{array}$ & $\begin{array}{l}0.08 \\
0.36\end{array}$ \\
\hline Trouble sleeping & $\begin{array}{l}\text { Pearson correlation } \\
P\end{array}$ & $\begin{array}{l}0.17^{*} \\
0.04\end{array}$ & $\begin{array}{c}-0.19 * \\
0.03\end{array}$ \\
\hline $\begin{array}{l}\text { Feeling tired or having } \\
\text { low energy }\end{array}$ & $\begin{array}{l}\text { Pearson correlation } \\
P\end{array}$ & $\begin{array}{l}0.08 \\
0.34\end{array}$ & $\begin{array}{c}-0.23^{*} \\
0.01\end{array}$ \\
\hline Diabetes & $\begin{array}{l}\text { Pearson correlation } \\
P\end{array}$ & $\begin{array}{l}0.19 * \\
0.03\end{array}$ & $\begin{array}{l}0.02 \\
0.85\end{array}$ \\
\hline Frequent swollen glands & $\begin{array}{l}\text { Pearson correlation } \\
P\end{array}$ & $\begin{array}{l}0.18^{*} \\
0.04\end{array}$ & $\begin{array}{l}0.06 \\
0.52\end{array}$ \\
\hline
\end{tabular}

${ }^{2}$ Total indoor time score was the total score from indoor time spent playing video games and watching television and indoor organized activity and sports. A higher score indicated more time was reported as spent indoors and a lower score indicated that less time was reported as spent indoors $(N=140)$.

yTotal outdoor time score was the total score from outdoor free play and outdoor organized activity and sports. A higher score indicated more time was reported as spent outdoors and a lower score indicated that less time was reported spent indoors $(N=140)$.

${ }^{\mathrm{x}} \mathrm{A}$ higher health problems score indicated more health problems were reported by the parent respondent. A lower health problems score indicated that fewer health problems were reported by parent respondent $(N=140)$.

* Statistically significant at the 0.05 level.

support of the research of Watanabe et al. (2006). No statistically significant relationships were found between time spent indoors or time spent outdoors and parents' reports of itchy watery eyes, ear infection or earache, cough, headache, cold, sore throat, body pain or discomfort, constipation, loose bowels, or diarrhea, limitations riding a bike, running, or playing sports, repeated upset stomach, nervousness, overweight or obesity, chest pain, loss of appetite, or back pain.

Time SPENT in VARIOUS ACTIVITIES AND HEALTH. A Pearson's product-moment correlation was calculated between scores calculated from respondents' reports of the time their children spent in various activities and their reports of their children's health problems. Only one statistically significant correlation was found-"how much time per day does your child spend indoors on video games or watching television?"-which was positively correlated with the overall health problems score (Table 2). This revealed that as respondents' reports of the time their children spent indoors playing video games and watching television increased, reports of the number of health problems children experienced also increased. This finding corroborates with other studies, which showed unhealthy effects from watching television (Blass et al., 2006; Coon et al., 2001). Specifically, television viewing was linked to higher body mass index, decreased heavy physical activity, and weaker cardio-respiratory fitness (Pettee et al., 2008).

Pearson's product-moment correlations were also calculated between respondents' reports of time their children spent in various activities and their reports of their children's individual health problems. Statistically significant correlations were found between several activities and health problems. Scores for "how many hours per day does your child spend outdoors in free play on average?" were negatively correlated with reports 
Table 2. Correlation matrix indicating the Pearson's product-moment correlation between outdoor free play score, outdoor organized activities or sports score, indoor organized activities or sports score and indoor video games or watching television score, and health problems in the study of the relationship between parental attitudes toward their child's outdoor recreation and their child's health.

\begin{tabular}{|c|c|c|c|c|c|}
\hline Health problem $^{z}$ & & $\begin{array}{l}\text { Outdoor } \\
\text { free play }\end{array}$ & $\begin{array}{l}\text { Outdoor organized } \\
\text { activities or sports }^{\mathrm{x}}\end{array}$ & $\begin{array}{l}\text { Indoor organized } \\
\text { activities or sports }^{w}\end{array}$ & $\begin{array}{l}\text { Indoor video games or } \\
\text { watching television }^{v}\end{array}$ \\
\hline \multirow[t]{2}{*}{ Overall } & Pearson correlation & -0.11 & 0.08 & 0.10 & $0.18 *$ \\
\hline & $P$ & 0.20 & 0.35 & 0.26 & 0.03 \\
\hline \multirow[t]{2}{*}{ Nasal congestion } & Pearson correlation & 0.06 & 0.14 & 0.14 & $0.19^{*}$ \\
\hline & $P$ & 0.46 & 0.09 & 0.09 & 0.02 \\
\hline & $P$ & 0.12 & 0.69 & 0.27 & 0.49 \\
\hline \multirow[t]{2}{*}{ Asthma attacks } & Pearson correlation & -0.03 & $0.18 *$ & $0.27^{*}$ & -0.01 \\
\hline & $P$ & 0.70 & 0.04 & 0.01 & 0.89 \\
\hline Cough & Pearson correlation & 0.07 & 0.08 & $0.17^{*}$ & -0.05 \\
\hline discomfort & $P$ & 0.01 & 0.59 & 0.53 & 0.14 \\
\hline \multirow[t]{2}{*}{ Trouble sleeping } & Pearson correlation & -0.16 & -0.13 & -0.01 & $0.24^{*}$ \\
\hline & $P$ & 0.06 & 0.14 & 0.87 & 0.01 \\
\hline \multirow{2}{*}{$\begin{array}{l}\text { Repeated upset } \\
\text { stomach }\end{array}$} & Pearson correlation & $-0.18^{*}$ & -0.04 & -0.04 & 0.09 \\
\hline & $P$ & 0.03 & 0.67 & 0.66 & 0.31 \\
\hline \multirow{2}{*}{$\begin{array}{l}\text { Feeling tired or } \\
\text { having low energy }\end{array}$} & Pearson correlation & $-0.29^{*}$ & -0.04 & -0.04 & 0.14 \\
\hline & $P$ & 0.01 & 0.67 & 0.66 & 0.10 \\
\hline $\begin{array}{l}\text { Frequent swollen } \\
\text { glands }\end{array}$ & Pearson correlation & -0.13 & $0.26^{*}$ & 0.09 & 0.15 \\
\hline
\end{tabular}

${ }^{2} \mathrm{~A}$ higher health problems score indicated more health problems were reported by the parent respondent. A lower health problems score indicated that fewer health problems were reported by parent respondents $(N=140)$.

y A higher outdoor free play score indicated more time was reported as spent outdoors in free play and a lower score indicated that less time was reported as spent outdoors in free play $(N=140)$.

xA higher outdoor organized activities or sports score indicated more time was reported as spent outdoors in organized activities or sports and a lower score indicated that less time was reported as spent outdoors in organized activities or sports $(N=140)$.

wA higher indoor organized activities or sports score indicated more time was reported as spent indoors in organized activities or sports and a lower score indicated that less time was reported as spent indoors in organized activities or sports $(N=139)$.

${ }^{v}$ A higher indoor video game or watching television score indicated more time was reported as spent indoors playing video games or watching television and a lower score indicated that less time was reported as spent indoors playing video games or watching television $(N=140)$.

*Statistically significant at the 0.05 level.

of body pain or discomfort, repeated upset stomach, and feeling tired or having low energy. Scores for the question "how many hours per day does your child spend outdoors in organized activities or sports on average?" were positively correlated with reports of asthma attacks and frequent swollen glands. Similarly, scores for the question "how much time per day does your child spend indoors in organized activities or sports" were positively correlated with reports of asthma attacks and cough. Finally, the question, "how much time per day does your child spend indoors on videos games or watching television?" was positively correlated with reports of nasal congestion and trouble sleeping (Table 2). In particular, the correlation with nasal congestion is interesting because of its occurrence as a symptom of allergies. In addition, allergies have been reported to cause sleep disturbances in children (Khan et al., 2001). No statistically significant relationships were found with regards to parents' reports of itchy watery eyes, ear infection or earache, headache, cold, sore throat, constipation, loose bowels or diarrhea, limitations riding a bike, running or playing sports, repeated upset stomach, nervousness, overweight or obesity, chest pain, loss of appetite, diabetes, or back pain.
Attitudes AND TOTAL TIME SPENT IN ACTIVITIES. Pearson's productmoment correlations were calculated between parents' attitudes, scores calculated based on time spent indoors and scores calculated from reported time spent outdoors.

The total time spent indoor score was negatively correlated with both the PAN score and the PACOR score. This indicated that the more positive parents' attitude toward nature and the more positive they were about their children's outdoor recreation, the less time they reported their children spending indoors. Also, the total time spent outdoors score was positively correlated with the PAN score (Table 
3). This showed that parents' who had higher PAN scores also reported that their children spent more time outdoors.

Pearson's product-moment correlations were calculated between the PAN score, the PACOR score, the outdoor free play score, the outdoor organized activities or sports score, the indoor organized activities or sports score, and the indoor video games or watching television score. Statistically significant but weak (Gall et al., 2006) positive correlations were found between the PAN score and the number of hours children spent outdoors in free play and between PACOR score and the number of hours children spent outdoors in free play. This indicated that as respondents' scores on the PAN scale increased and as their scores on the PACOR scale increased, so did the number of hours their children spent outdoors in free play (Table 4). This is also logical, in that parents who have more positive attitude about nature and about their children spending time outdoors will be more willing to allow and help their children have more outdoor play time. Beets et al. (2007) found that this support was an important factor in determining both daughters' and sons' outdoor activity time. No statistically significant relationships were found between the PAN and PACOR on the time spent outdoors in organized sports and activities, indoors in organized sports and activities, and indoors playing video games or watching television.

Demographic analysis. Frequencies, $t$ tests, and analysis of variance were run in SPSS $\AA$ (version 15.0) to determine if gender of the respondent or child, ethnicity, marital status, residential area type, education level, or income level had any effect on the respondents' scores on the research variables. No significant differences were found on any of the variables (Table 5). Therefore, parents in terms of demographics were considered homogenous, and thus the data were not separated out into any demographic groups.

\section{Conclusions}

With the increasing concerns regarding health problems for children, particularly in the United States, parental decisions about childhood activity are becoming critically important.

Table 3. Correlation matrix indicating the Pearson's product-moment correlation between parental attitude toward nature score, parental attitude toward their child's outdoor recreation score, the total indoor time score, and the total outdoor time score in the study of the relationship between parental attitudes toward their child's outdoor recreation and their child's health.

\begin{tabular}{|c|c|c|c|}
\hline Attitudinal scale & & $\begin{array}{l}\text { Total indoor } \\
\text { time score }\end{array}$ & $\begin{array}{l}\text { Total outdoor } \\
\text { time score }\end{array}$ \\
\hline $\begin{array}{l}\text { Parental attitude toward } \\
\text { nature scale }\end{array}$ & $\begin{array}{l}\text { Pearson correlation } \\
P\end{array}$ & $\begin{array}{c}-0.21 * \\
0.01\end{array}$ & $\begin{array}{l}0.21 * \\
0.01\end{array}$ \\
\hline $\begin{array}{l}\text { Parental attitude toward } \\
\text { their child's outdoor } \\
\text { recreation scale }\end{array}$ & $\begin{array}{l}\text { Pearson correlation } \\
P\end{array}$ & $\begin{array}{c}-0.17^{*} \\
0.04\end{array}$ & $\begin{array}{l}0.11 \\
0.21\end{array}$ \\
\hline
\end{tabular}

${ }^{2}$ Total indoor time score was the total score from indoor time spent playing video games and watching television and indoor organized activity and sports. A higher score indicated more time was reported as spent indoors and a lower score indicated that less time was reported as spent indoors $(N=140)$.

y Total outdoor time score was the total score from outdoor free play and outdoor organized activity and sports. A higher score indicated more time was reported as spent outdoors and a lower score indicated that less time was reported spent indoors $(N=140)$

${ }^{x}$ Higher parental attitude toward nature scores indicated a positive view toward nature and lower scores indicated a less positive view toward nature $(N=140)$

"Higher parental attitude toward their child's outdoor recreation scores indicated parents had a more positive view of their children spending time outdoors, and lower scores indicated less positive view $(N=140)$.

* Statistically significant at the 0.05 level.

Table 4. Correlation matrix indicating the Pearson's product-moment correlation between parents attitude toward nature score, parental attitude toward their child's outdoor recreation score, and outdoor free play score in the study of the relationship between parental attitudes toward their child's outdoor recreation and their child's health.

\begin{tabular}{lccc}
\hline Activities & & $\begin{array}{c}\text { Parental attitude } \\
\text { toward nature } \\
\text { scale }^{\mathrm{z}}\end{array}$ & $\begin{array}{c}\text { Parental attitude } \\
\text { toward their child's } \\
\text { outdoor recreation scale }\end{array}$ \\
\hline $\begin{array}{l}\text { How many hours } \\
\text { per day does your } \\
\begin{array}{l}\text { child spend outdoors } \\
\text { in free play on average? }\end{array}\end{array}$ & $\begin{array}{c}\text { Pearson } \\
\text { correlation }\end{array}$ & 0.22 & 0.17 \\
\hline
\end{tabular}

${ }^{\mathrm{z}}$ Higher parental attitude toward nature scores indicated a positive view toward nature and lower scores indicated a less positive view toward nature.

yigher parental attitude toward their child's outdoor recreation scores indicated parents had a more positive view of their children spending time outdoors, and lower scores indicated less positive view.

${ }^{\mathrm{x}} \mathrm{A}$ higher outdoor free play score indicated more time was reported as spent outdoors in free play and a lower score indicated that less time was reported as spent outdoors in free play $(N=140)$.

* Statistically significant at the 0.05 level.

Chronic diseases in children on the rise such as asthma (Akinbami, 2006) and obesity (National Center for Health Statistics, 2010a) are putting childhood activity levels and parental involvement in childhood activity under scrutiny.

Results from this study showed that most respondents reported a positive view about both nature and allowing their children to play outdoors. The more positive a parent was about nature and about their children spending time outdoors, the more time the child played outdoors in free play. Additionally, the more positive parents were about nature and their children spending time in it, the less time their children spent indoors in any activity.
Parents' attitudes about letting their children spend time outdoors was not related to their reports of their children's health problems. However, the amount of time children spent indoors on video games or watching television had a weak positive relationship with the children's health problem scores, revealing that the more time children spent indoors watching television and playing video games, the more health problems they experienced.

Individually, several health problems were significantly correlated with the different activities. Body pain or discomfort, repeated upset stomach, and feeling tired or having low energy all decreased if the child spent more time outdoors in free play. 
Reports of asthma attacks increased with the more time a child spent in organized sports or activities, regardless of whether those activities took place indoors or outdoors. Also, swollen glands were reported more frequently according to the number of hours per day children spent outdoors in organized activities, whereas coughing increased according to the number of hours children spent indoors in organized sports.

Finally, children who spent more time indoors playing video games or watching television were more likely to suffer from the health problems of nasal congestion and having trouble sleeping. Also, children who spent more time indoors were more likely to suffer from asthma attacks, diabetes, and frequent swollen glands.

Additional research to alleviate the limitations of this study would be useful to verify the representativeness of these results. This survey had a limited sample of those parents who accessed the survey from a gardening-related website, indicating those who responded had some interest, question, or concern about the outdoors or nature to be perusing this website. Conducting the survey in print form with a broader sample would improve the generalizability of the results. Because of the constraints of this survey, a bias may be present in the responses received and a broader sample may provide more variability in scores on the PAN and PACOR. With the results of this study, one could hypothesize that such a correlation would continue to exist in populations with lower PAN and PACOR scores.

Since parents who had more positive attitudes toward nature tended to have children who participated more in outdoor activities, it may be valuable to develop programs targeting this relationship between parents and nature in helping to remediate the health epidemics facing the children of the United States. Gardening programs are one example of an outdoor activity that can be either structured or unstructured, which could provide children with the opportunity to partake in outdoor activities in a safe setting. Future experimental research would help to understand the full impact of environmental programming for parents on their children's health.
Table 5. Demographic analysis of the overall sample by gender of parent, gender of child, ethnicity, marital status, residential area, education level, and income level in the study of the relationship between parental attitudes toward outdoor environments, their children spending time outdoors and their children's overall health.

\begin{tabular}{lrccc}
\hline & \multicolumn{2}{c}{$\begin{array}{c}\text { Parental } \\
\text { attitude } \\
\text { toward nature } \\
\text { mean score }\end{array}$} & $\begin{array}{c}\text { Parental attitude } \\
\text { toward their child's } \\
\text { outdoor recreation } \\
\text { mean score }\end{array}$ & $\begin{array}{c}\text { Mean number } \\
\text { of health } \\
\text { problems } \\
\text { reported }\end{array}$ \\
\hline $\begin{array}{l}\text { Demographic variable } \\
\text { Gender of respondent }\end{array}$ & $N$ & & & \\
$\quad \begin{array}{l}\text { Male } \\
\text { Female }\end{array}$ & 118 & 106.95 & 150.50 & 1.41 \\
$\begin{array}{l}\text { Total } \\
P\end{array}$ & 140 & 109.82 & 151.73 & 1.74 \\
$P$ & & 0.28 & 0.94 & 0.60
\end{tabular}

Gender of child

$\begin{array}{lrrrr}\text { Male } & 81 & 108.51 & 152.10 & 1.89 \\ \text { Female } & 59 & 110.56 & 150.76 & 1.41 \\ \text { Total } & 140 & & & \\ P & & 0.61 & 0.88 & 0.28\end{array}$

Ethnicity

White

119

109.51

152.53

1.71

Hispanic

107.09

African American

107.20

Native American

114.00

Asian

0

None of those listed

Total

116.00

P

0.82

143.73

143.00

164.00

0

148.00

1.27

1.40

6

0

1

Parent marital status

Single/never married

Married/partnered

1

104.00

108.95

Separated

0

Divorced

0

Widowed

111.86

Total

112.00

0.13

0.26

P

0.84

134.00

5.00

152.09

0

149.26

1.70

0

144.00

1.48

1.00

0.74

0.30

Residential area

Rural

Suburban

109.73

108.44

Urban

113.00

Inner-city

106.67

Total

0.80

153.80

1.93

151.15

149.00

1.72

139.67

1.00

1.33

$P$

0.64

0.80

Education level of respondent Less than high school 3 High school graduate 12

115.33

153.67

0

112.17

Some college

111.32

4-year college degree

108.12

150.25

1.75

151.80

152.12

1.50

Graduate school

107.20

151.77

1.80

Total

140

$P$

0.38

0.52

0.55

Annual income

Less than $\$ 9,999$

\$10,000-\$14,999

$\$ 15,000-\$ 24,999$

118.00

158.00

7.00

137.00

1.50

106.60

140.20
1.40 
Table 5. (Continued) Demographic analysis of the overall sample by gender of parent, gender of child, ethnicity, marital status, residential area, education level, and income level in the study of the relationship between parental attitudes toward outdoor environments, their children spending time outdoors and their children's overall health.

\begin{tabular}{|c|c|c|c|c|}
\hline Demographic variable & $N$ & $\begin{array}{c}\text { Parental } \\
\text { attitude } \\
\text { toward nature } \\
\text { mean score } \\
\end{array}$ & $\begin{array}{l}\text { Parental attitude } \\
\text { toward their child's } \\
\text { outdoor recreation } \\
\text { mean score }\end{array}$ & $\begin{array}{c}\text { Mean number } \\
\text { of health } \\
\text { problems } \\
\text { reported } \\
\end{array}$ \\
\hline$\$ 25,000-\$ 34,999$ & 15 & 111.20 & 151.67 & 1.73 \\
\hline$\$ 35,000-\$ 49,999$ & 23 & 112.65 & 151.43 & 1.26 \\
\hline$\$ 50,000-\$ 74,999$ & 24 & 106.33 & 151.50 & 2.13 \\
\hline$\$ 75,000-\$ 99,999$ & 22 & 111.23 & 151.36 & 1.32 \\
\hline$\$ 100,000-\$ 149,999$ & 30 & 107.43 & 151.43 & 1.63 \\
\hline More than $\$ 150,000$ & 14 & 106.71 & 156.57 & 1.57 \\
\hline Total & 136 & & & \\
\hline$P$ & & 0.35 & 0.47 & 0.27 \\
\hline
\end{tabular}

\section{Literature cited}

Akinbami, L.J. 2006. The state of childhood asthma, United States, 1980-2005. Adv. Data Vital Health Stat. 381:1-24.

American Academy of Allergy Asthma and Immunology. 2011. Allergy statistics. 19 Feb. 2011. <http://www.aaaai.org/media/ statistics/allergy-statistics.asp >.

Beets, M.W., R. Vogel, S. Chapman, K.H. Pitetti, and B.J. Cardinal. 2007. Parent's social support for children's outdoor physical activity: Do weekdays and weekends matter? Sex Roles. 56:125-131.

Blass, E.M., D.R. Anderson, H.L. Kirkorian, T.A. Pempek, I. Price, and M.F. Koleini. 2006. On the road to obesity: Television viewing increases intake of high-density foods. Physiol. Behav. 88:597-604.

Chawla, L. 2002. Growing up in an urbanizing world. Earthscan, London.

Clements, R. 2004. An investigation of the status of outdoor play. Contemp. Issues Early Child 5:68-80.

Cohen, J. 1992. A power primer. Psychological Bul. 112:155159.

Coon, K.A., J. Goldberg, B.L. Rogers, and K.L. Tucker. 2001. Relationships between use of television during meals and children's food consumption patterns. Pediatrics 107. 29 Sept. 2010. <http://pediatrics. aappublications.org/cgi/content/full/ $107 / 1 / \mathrm{e} 7>$.

Dravigne, A., T.M. Waliczek, R.D. Lineburger, and J.M. Zajicek. 2008. The effect of live plants and window views of green spaces on employee perceptions of job satisfaction. HortScience. 43:183187.

Ennis, T. 2003. Parental attitudes towards the importance of recreation for their children with disabilities. Laurentian Univ., Sudbury, ON, Canada, PhD Diss. Abstr. AAT MQ85633.

Farley, T.A., R.A. Meriwether, E.T. Baker, L.T. Watkins, C.C. Johnson, and L.S. Webber. 2007. Safe play spaces to promote sults from a pilot study of an environmental intervention. Amer. J. Public Health 97:1625-1631.

Frumkin, H. 2001. Beyond toxicity. Amer. J. Prev. Med. 20:234-240.

Gall, M.D., W.R. Borg, and J.P. Gall. 2006. Educational research: An introduction. 8th ed. Allyn \& Bacon, White Plains, NY.

Halken, S. 2003. Early sensitization and development of allergic airway disease-risk factors and predictors. Paediatr. Respir. Rev. 4:128-134.

Hofferth, S. and J.F. Sandberg. 2001. How American children spend their time. J. Marriage Fam. 63:295-308.

Juster, T.F., H. Ono, and F.P. Stafford. 2004. Changing times of American youth: 1981-2003. Inst. Social Res., Univ. Michigan, Ann Arbor.

Khan, A., M.J. Mozin, J. Groswasswer, M. Sottiaux, B. Dan, S. Scaillet, G. Casimir, and J. Duchateau. 2001. Sleep disorders and childhood allergy, p. 137-139. In: G. Stores and L. Wiggs (eds.). Sleep disturbance in children and adolescents with disorders of development: Its significance and management. High Holborn House, London.

Kohlleppel, T., J.C. Bradley, and S. Jacob. 2002. A walk through the garden: Can a visit to a botanic garden reduce stress? Hort Technology 12:489-492.

Korpela, K. 2002. Children's environment, p. 363-73. In: R. Bechtel and A. physical activity in inner-city children: Re-
Churchman (eds.). Handbook of environmental psychology. Wiley, New York.

Liberatos, P. 2007. Pathways to poor health outcomes for children of low income teen mothers. Columbia Univ. New York, PhD Diss. Abstr. AAT 3266628.

Likert, R. 1967. The method of constructing an attitude scale, p. 90-95. In: M. Fishbein (ed.). Readings in attitude theory and measurement. Wiley, New York.

Ludvigsson, J., K. Huus, K. Eklo, R. Klintstro, and A. Lahdenpera. 2007. Fasting plasma glucose levels in healthy preschool children: Effects of weight and lifestyle. Acta Paediatr. 96:706-709.

McFarland, A.L., D.E. Hammond, J.M. Zajicek, and T.M. Waliczek. 2011. Growing minds: The development of an instrument to measure parental attitude toward nature and their child's outdoor recreation. HortTechnology. 21:225-229.

McMillan, T.E. 2003. Walking and urban form: Modeling and testing parental decisions about children's travel. Univ. California, Irvine, PhD Diss. Abstr. AAT 3090273n.

Molnar, B.E., S.L. Gortmaker, C.F. Bull, and S.L. Buka. 2004. Unsafe to play? Neighborhood disorder and lack of safety predict reduced physical activity among urban children and adolescents. Amer. J. Health Promot. 18:378-386.

Murphy, K.R. 1984. Family patterns of use and parental attitudes toward home electronic video games and future technology. Oklahoma State Univ., Stillwater, PhD Diss. Abstr. AAT 8515283.

National Center for Health Statistics. 2010a. Prevalence of overweight, obesity, and extreme obesity among adults: United States, trends 1976-1980 through 2007-2008. 29 Sept. 2010. <http://www.cdc.gov/ NCHS/data/hestat/obesity_adult_07_08/ obesity_adult_07_08.pdf>.

National Center for Health Statistics. $2010 \mathrm{~b}$. Prevalence of overweight and obesity among children and adolescents: United States, trends 1963-1965 through 20072008. 29 Sept. 2010. <http://www.cdc. gov/nchs/data/hestat/obesity_child_07_08/ obesity_child_07_08.pdf $>$.

Pettee, K.K., S.A. Ham, C.A. Macera, and B.E. Ainsworth. 2008. The reliability of a survey question on television viewing and associations with health risk factors in U.S. adults. Intl. J. Obes. 17:487-493.

Piotrowski, D.A. 2007. Factors associated with young children's home video game habits. New York State Univ., Buffalo, PhD Diss. Abstr. AAT 3261962.

Proctor, M.H., L.L. Moore, D. Gao, L.A. Cupples, M.L. Bradlee, M.Y. Hood, and 


\section{Research Reports}

R.C. Ellison. 2003. Television viewing and change in body fat from preschool to early adolescence: The Framingham Children's Study. Intl. J. Obes. 27:827-833.

Ring, J., U. Kramer, T. Schafer, and H. Behrendt. 2001. Why are allergies increasing? Curr. Opin. Immunol. 13:701-708.

Skelly, S. 1997. The effect of project green, an interdisciplinary garden program, on the environmental attitudes of elementary school students. Texas A\&M Univ., College Station, MS Thesis.

Texas A\&M University. 2009. Web Server Statistics for Aggie Horticulture. 19 Feb. 2011. <http://aggie-horticulture.tamu. edu/webstat/analog/report_apr09.html >.

Timperio, A., D. Crawford, A. Telford, and J. Salmon. 2004. Perceptions about the local neighborhood and walking and cycling among children. Prev. Med. 38:39-47.

Valentine, G. and J. McKendrick. 1997. Children's outdoor play: Exploring parental concerns about children's safety and the changing nature of childhood. Geoforum 28:219-235.

Veitch, J., S. Bagley, K. Ball, and J. Salmon. 2006. Where do children usually play? A qualitative study of parents' perceptions of influences on children's active free-play. Health Place 12:383-393.

Waliczek, T.M., R.H. Mattson, and J.M Zajicek. 1996. Benefits of community gardening on quality-of-life issues. J. Environ. Hort. 14:204-209.
Watanabe, M., K. Nakamura, Y. Fukuda, and T. Takano. 2006. Association of parental and children behaviors with the health status of preschool children. Prev. Med. 42:297-300.

Weir, L.A., D. Etelson, and D.A. Brand. 2006. Parents' perceptions of neighborhood safety and children's physical activity. Prev. Med. 43:212-217.

Wells, N. and G.W. Evans. 2003. Nearby nature a buffer of life stress among rural children. Environ. Behav. 35:311-330.

Welsh, D. 2006. Occupational stress, selfefficacy and symptom relationships among medical-surgical hospital nurses. Univ. of Kentucky, Lexington, PhD Diss. Abstr. AAT 3259209. 